\title{
Modeling and analysis of temperature distribution in the multilayer metal composite structures in grinding
}

\author{
V. A. Pashnyov ${ }^{1}$ - D. Yu. Pimenov ${ }^{2}$ I. N. Erdakov ${ }^{3}$ - M. S. Koltsova ${ }^{2}$ - T. Mikolajczyk ${ }^{4}$. \\ K. Patra ${ }^{5}$
}

Received: 1 November 2016 / Accepted: 9 January 2017 /Published online: 7 February 2017

(C) The Author(s) 2017. This article is published with open access at Springerlink.com

\begin{abstract}
The article covers a mathematical model of a temperature distribution in the three-layer metal composite structures when grinding their working layers. The computer program TEMSS, created on the basis of thermal models, allows calculation of all the characteristics of the temperature distribution in the layers of the metal composite structure, depending on the system structure, material properties of its layers, grinding and machining conditions, and duration. The work establishes the adequacy of the developed mathematical mod-
\end{abstract}

D. Yu. Pimenov

danil_u@rambler.ru

V. A. Pashnyov

alich74@rambler.ru

I. N. Erdakov

wissenschaftler@bk.ru

T. Mikolajczyk

tami@utp.edu.pl

K. Patra

kpatra@iitp.ac.in

1 Department of Metallurgical Industry, South Ural State University, St. Mira, 23, Chelyabinsk region Asha 456010, Russia

2 Department of Automated Mechanical Engineering, South Ural State University, Lenin Prosp. 76, Chelyabinsk 454080, Russia

3 Department of Pyrometallurgical and Casting Technologies, South Ural State University, Lenin Prosp. 76, Chelyabinsk 454080, Russia

4 Department of Production Engineering, UTP University of Science and Technology, Al. Prof. S. Kaliskiego 7,

85-796 Bydgoszcz, Poland

5 Department of Mechanical Engineering, Indian Institute of Technology Patna, Bihta, Patna 801103, India el of the temperature distribution when grinding the metal composite systems. The article covers the analysis of standard metal composite systems with Loctite, Chester molecular, and Devcon polymers on the basis of the temperature distribution model, revealing the influence of lamination on the nature of the temperature distribution. Critical temperatures are defined that determine the occurrence of thermal grinding defects in the metal composite system, including their dependencies on processing conditions and the system structure. Thus, it is found that when grinding a working steel layer of the composite system using the standard grinding conditions recommended in the reference handbooks for steel workpieces, the temperature in the working and polymer-composite layers, as a rule, exceeds the threshold values for these materials.

Keywords Metal composite structures · Polymer composite materials $\cdot$ Machining $\cdot$ Grinding $\cdot$ Finishing $\cdot$ Temperature

\section{Nomenclature}

D Working surface diameter (cutting diameter) (mm)

$\mathrm{h} \quad$ Working layer thickness $(\mathrm{mm})$

$\delta \quad$ Polymer composite layer thickness (mm)

$V_{\text {Srad }} \quad$ Radial feed of the grinding disk $(\mathrm{mm} / \mathrm{min})$

$V_{\mathrm{C}} \quad$ Cutting speed $(\mathrm{mm} / \mathrm{s})$

$L_{C} \quad$ Contact arc length of the grinding disk with the workpiece (mm)

$\Delta \quad$ Radial machining allowance ( $\mathrm{mm})$

$\mathrm{n} \quad$ Rotational frequency of the workpiece (rpm)

$\omega \quad$ Angular velocity $\left(\mathrm{s}^{-1}\right)$

$U_{i} \quad$ Temperature at the boundary of the $i$ th layer $\left(\mathrm{K},{ }^{\circ} \mathrm{C}\right)$

$U_{\text {cr }} \quad$ Critical temperature maxima $\left({ }^{\circ} \mathrm{C}\right)$

$C \quad$ Specific heat capacity $(\mathrm{J} /(\mathrm{kg} \mathrm{K}))$

$\lambda \quad$ Thermal conductivity $(\mathrm{W} /(\mathrm{m} \mathrm{K}))$

$\rho \quad$ Density $\left(\mathrm{kg} / \mathrm{m}^{3}\right)$ 
$\nu_{i} \quad$ Internal distributed heat transfer coefficient for side surface $\left(\mathrm{W} / \mathrm{m}^{2} \mathrm{~K}\right)$

$\alpha \quad$ Heat transfer coefficient $\left(\mathrm{W} / \mathrm{m}^{2} \mathrm{~K}\right)$

$q \quad$ Intensity of heating source $\left(\mathrm{W} / \mathrm{m}^{2}\right)$

$l_{i} \quad i$ th layer thickness ( $\left.\mathrm{mm}\right)$

$\sqrt{\chi} / \lambda \quad$ Parameter presenting the heat generation on the surface during grinding

$\chi \quad$ Thermal diffusivity $(\chi=\lambda / C \rho)\left(\mathrm{m}^{2} / \mathrm{s}\right)$

$R_{i} \quad$ Radial coordinates of the layer boundaries (mm)

$2 \Delta \quad$ Diametrical machining allowance $(\mathrm{mm})$

$N_{\text {sp }} \quad$ Specific (intensity) power rating $(\mathrm{kW} / \mathrm{mm})$

$f_{r} \quad$ Feed per revolution $(\mathrm{mm} / \mathrm{rev})$

$t \quad$ Time (s)

$\tau \quad$ Time for passing contact arc length $L_{c}(\mathrm{~s})$

$T \quad$ Time for completing one turn of the working surface during grinding (s)

$d \quad$ Cutting depth per turn ( $\mathrm{mm})$

\section{Introduction}

In modern technical solutions, layered metal composite structures are used for aerospace technologies, in engineering, and metallurgical industries. A layered system on the basis of a metal and polymer composite materials (PCMs) is understood as a structure consisting of layers of metal and polymer composite materials. As a rule, the basic material of the structure is metal. The working surfaces are formed by a system of layers made of polymer composite materials and metals. Such composite systems are described in [1, 2].

The simplest variant of a layered structure is the covering made of a polymer composite material described in [3, 4].

These systems are used for the repair of heavily loaded parts with working surfaces subjected to great contact loads. These solutions are required upon restoration of worn-out bearing necks of shafts of rolling mills, spindles, and in the process of restoring the equipment or its elements, described in works [5-11].

Nowadays, there are over 400 brands of industrial PCMs in the world market, such as «Belzona» (USA), «Multimetall» (Germany), «Diamant» (Germany), «Loctite» (USA), «Devcon» (USA), «Unirep» (Germany), «Leo» (Russia), «Chester molecular» (Poland-Russia), «Desan» (Russia), «Polirem» (Russia), and «Rekom» (Russia).

Examples of using the materials mentioned are given in the works below. The work [9] reports on using Belzona PCMs in repair technologies. The article [10] covers results of tests for bonding strength of Loctite epoxy composites. The work [11] presents the use of Araldite, Epibond, and Loctite bonded joints in the automotive and aerospace industries. The article [12] gives experimental research on stress during delamination of a plastic layer ULTEM-1000 from Kovar nickel alloy bonded using Devcon polymer. The work [13] analyzes stress fields providing bearing capacity of a metal composite structure with a polymer binder.

When developing repair technologies using PCMs, the physical and mechanical properties of the structural material should be compared to the PCM properties. The strength of industrial PCMs is less than structural steels and alloys, according to [14-17]. Besides, the strength properties of PCMs depend on the mode of load application. PCM compression strength exceeds by five times its tensile strength. The strength of pulling PCM off steel is 10 times less than its tensile strength.

Thermal characteristics of PCMs according to [18, 19] differ from thermal characteristics of structural materials as follows: PCMs' thermal capacity is 30 times less than that of steel; their thermal conductivity is 2.5 to 4 times less than that of ferrous metals and 100 times less than that of non-ferrous metals.

Industrial PCMs, according to [10, 14, 15], have thermal resistance thresholds equal to 100 to $230{ }^{\circ} \mathrm{C}$. In addition, some PCMs have descending thermal strength properties.

As mentioned in $[14,20]$, the accuracy of the working surfaces of shaft pins for bearings reaches the fifth to eighth quality class.

After polymerization of the PCM layer, machining (turning of shafts or boring of holes) $[21,22]$ is basically carried out. However, turning or boring of metal composite structures of such high accuracy has a low productivity. Therefore, turning (rough and fine), turning with subsequent grinding, and grinding $[23,24]$ are used for finishing shaft necks and holes.

The finishing of metal composite structures, according to [10], includes grinding. An analysis of the repair technologies showed that during grinding of the working layer of the metal composite structure in modes recommended for grinding metals in the handbook, the specific defect known as a burn of ground metal appears.

In this case, it is necessary to eliminate the risk of possible burns during grinding, which can appear if the permitted upper temperature limits in the polymer composite system are exceeded. To maintain the grinding temperature below permitted upper limit or the glass transition temperature of the polymer, coolant is to be applied or feed rate is to be decreased [25]. Earlier attempts were also made to decrease grinding temperature of polymer composites either by using electroplated wheel with controlled abrasive cluster [26] or by applying internal coolant through grinding wheel [27]. However, detailed mathematical model of the temperature distribution in the metal-polymer composite layered structure during grinding of its working layer has to be developed to understand the effects of different grinding and workpiece material parameters on grinding temperature to avoid grinding burns [28].

The thermal physics of the grinding process is highly elaborated in the recent literature [29, 30]. There are many mathematical models describing the temperature distribution 
during grinding of metals and ceramics [31-34]. Numerical solutions for temperature distribution for hardening grinding of steel components are given in [32]. But the solution fits only a limited dimension range and material combinations. In [33], an analytical model was applied to simulate the evolution of temperature during grinding of titanium alloy. Numerical simulations of grinding temperature distribution in three different materials, namely, 45 steel, $2 \mathrm{Cr} 13$, and zirconia ceramics, were shown in [34]. Furthermore, effects of grinding depth, cooling, and lubrication on grinding temperature were also simulated. However, experimental validations of simulated grinding temperature distribution were not reported in these earlier works. Limited works only been reported so far on the mathematical modeling of grinding temperature distribution for laminated structures of metal and polymer composite materials [28, 35]. In [28], Shmidt and Dyakonov applied a two-dimensional formulation of the thermophysical model to simulate the temperature distribution in different metal-polymer composite laminar structures. The same authors later on proposed a numerical solution scheme to solve thermophysical model of laminated system of polymer composite materials [35]. However, the experimental confirmations of the adequacy of the proposed models on both cases were not included. Moreover, numerical solution scheme proposed therein is complex and requires additional software for simulating temperature distribution in different layers of the metal-polymer composite materials.

The research objective of the present work is to develop a temperature distribution model of the metal-polymer composite structure and to carry out analysis during grinding of the working steel layer using standard grinding modes for steel workpieces. An in-house developed special programming module "TEMSS" has been applied to simulate evolution of temperature on metal polymer interfaces and temperature distribution in the multilayer structure. The present work also develops an experimental scheme using thermocouple to measure grinding temperature for confirming adequacy of the proposed modeling and analysis scheme.

\section{Theory}

\subsection{Calculation scheme and mathematical description of the temperature distribution in the metal composite structure during grinding}

The thermal physics of grinding uses two approaches to the calculation of the temperature distribution in the grinding area; the scheme of discrete contact in which thermal pulse carriers are considered to be cutting grains of the grinding disk on the contact arc is used in [28]. The scheme of flush contact, when the thermal source is a geometric contact zone of the grinding disk with the workpiece, is described in [36, 37].
The areas of application of these calculation schemes are reported in [38]. According to these recommendations, a simplified scheme of flush contact is permissible for determining burnless modes and analyzing deep heating (over $0.5 \mathrm{~mm}$ ).

When grinding cylindrical metal composite structures, the scheme of cylindrical external grinding with radial infeed is basically used, as described in [13, 14] (Fig. 1).

In terms of thermal physics, such a configuration lends itself naturally to a two-dimensional calculation scheme in circular coordinates (Fig. 2).

Following the calculation scheme, we have an intensity of heat source, $q$, distributed in an arc of contact $L_{C}$. Beyond the thermal source boundaries, the heat is transferred to the medium with the heat transfer coefficient $\alpha$ (as a result of the cutting fluid influence). The temperature distribution in the thermal source is propagating in the material rotating with angular velocity $\omega$. Therefore, the temperature distribution is formed not only due to conductive heat transfer within the material but also as a result of convective diffusion outside the cylinder.

To simplify the problem, let us consider kinematic and geometric correlations of the process. If the fixed coordinates

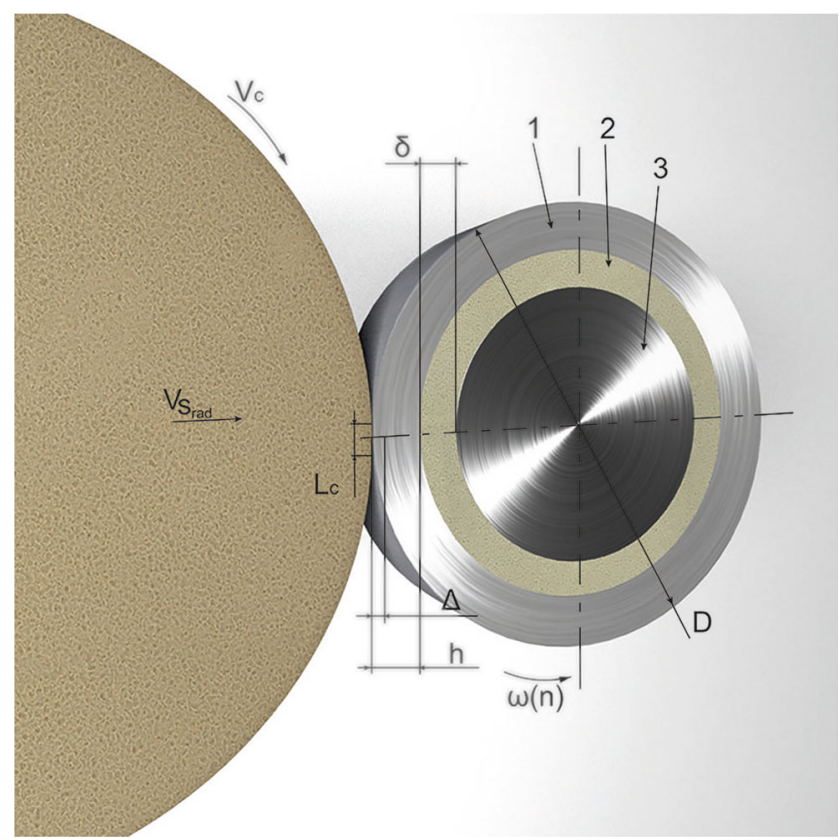

Fig. 1 Cylindrical external grinding with radial in-feed kinematic scheme, where $D$ is the working surface diameter (cutting diameter; $\mathrm{mm}) ; V_{S \mathrm{Sad}}$ is the radial feed of the grinding disk $(\mathrm{mm} / \mathrm{rev}) ; V_{\mathrm{C}}$ is the cutting speed $(\mathrm{m} / \mathrm{s}) ; L_{C}$ is the arc of contact of the grinding disk with the workpiece $(\mathrm{mm}) ; \mathrm{h}$ is the working layer thickness $(\mathrm{mm}) ; \delta$ is the polymer composite layer thickness $(\mathrm{mm}) ; \Delta$ is the radial allowance $(\mathrm{mm}) ; \mathrm{n}$ is the rotational frequency of the workpiece (rpm); and $\omega$ is the angular velocity $\left(\mathrm{s}^{-1}\right)$, where $\omega=2 \pi n / 60.1$ working layer, 2 PCM layer, 3 basic layer of the structure 


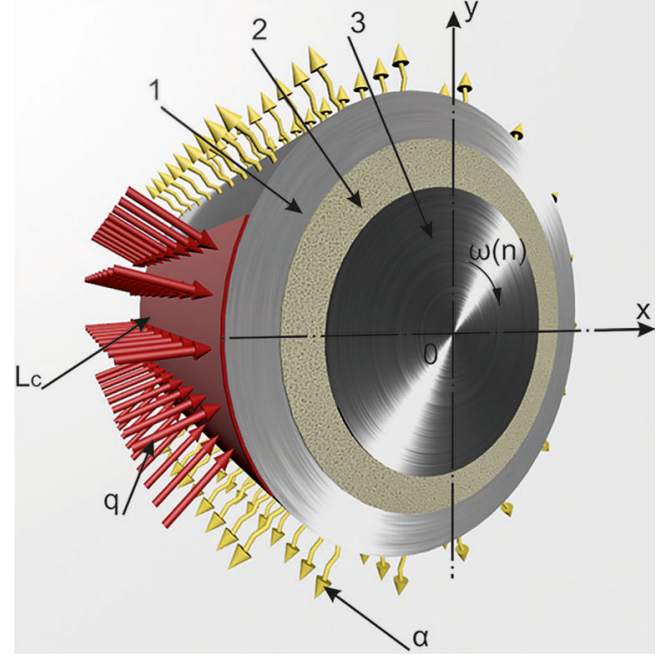

Fig. 2 The two-dimensional calculation scheme, where $\alpha$ is the heat transfer coefficient and $q$ is the intensity of heat source

are changed for moving ones, related to the part, the result is a moving thermal source to cover entire circumference of the workpiece during grinding.

The process is described with a differential equation of thermal conductivity with heat convection term. After transferring to moving coordinates, such problems of the thermal physics of grinding are traditionally transformed into onedimensional problems of thermal conductivity with a semiinfinite core. Alternation of thermal source activity and heat transfer to the process liquid is described as a time function; i.e., a mixed boundary value problem is set.

By analogy with the above, a one-dimensional calculation scheme (Fig. 3) is set for thermal conductivity in the layered system. The problem is given for the core of finite length 1 . The core is divided into $n$ parts, having individual thermal and physical properties. The source intensity $q$ and heat transfer coefficient $\alpha$ are distributed in time in compliance with the workpiece section being in the grinding zone or out of it.

To consider heat dissipation, each $i$ th layer of the workpiece body is fitted with the internal distributed heat transfer coefficient of side surface $\nu_{i}$. The thermal conductivity equation for the scheme is as follows: $\left.C \rho U_{t}=\lambda U_{\mathrm{xx}}-\nu U x \in[0, l]\right]$. The initial condition is $U(x, 0)=0$. The boundary conditions are as follows: for the left end of the core $(x=0)$, a compound condition $\lambda U_{x}(0, t)=i \alpha U(0, t)-(1-i) q(t)$ is set, describing the source intensity $q$ activity at $i=1$ and heat transfer coefficient $\alpha$ at $i=0$; for the right end, the additional condition of the third kind ( $\alpha$ with depth of the workpiece) $\lambda U u_{x}(l, t)=-\alpha U(l, t)$ is set. Thermal and physical constants $C_{i}, \rho_{i}, \lambda_{i}$, and $\nu_{i}$ are considered to be piecewise constants at each interval $\left(x_{i}, x_{i+1}\right)$. This integrated setup describes the heat transfer in the $n$-layered system.

A set of three thermal conductivity equations (for each layer of the system) can be used for the calculation scheme,

$$
\begin{array}{ccc}
\begin{array}{c}
\text { Workinglayer } \\
\frac{\partial U_{1}}{\partial t}=\chi_{1}^{2} \cdot \frac{\partial^{2} U_{1}}{\partial X_{1}^{2}} ;
\end{array} & \begin{array}{c}
\text { PCMlayer } \\
\partial t
\end{array}=\chi_{2}^{2} \cdot \frac{\partial^{2} U_{2}}{\partial \bar{X}_{2}^{2}} ; & \frac{\partial U_{3}}{\partial t}=\chi_{3}^{2} \cdot \frac{\partial^{2} U_{3}}{\partial \bar{X}_{3}^{2}} ; \\
0 \leq \bar{X}_{1}<\bar{l}_{1} ; & 0 \leq \bar{X}_{2}<\bar{l}_{2} ; & 0 \leq \bar{X}_{3}<\infty
\end{array}
$$

where initial temperature is considered to be equal for all the layers,

$U_{1}\left(\overline{X_{1}}, 0\right)=0 \quad U_{2}\left(\overline{X_{2}}, 0\right)=0 \quad U_{3}\left(\overline{X_{3}}, 0\right)=0$

The heat supply and transfer on the left boundary of the first layer are described as follows:
Fig. 3 The calculation scheme of heat transfer in the layered system, where $\lambda_{i}$ is the thermal conductivity, $C_{i}$ is the specific heat capacity of $i$ th layer $(\mathrm{kJ} /$ $\mathrm{kg} \mathrm{K}), \rho_{i}$ is the layer mass density, $\nu_{i}$ is the internal distributed heat transfer coefficient of side surface $\left(\mathrm{W} / \mathrm{m}^{2} \mathrm{~K}\right)$, and $l_{i}$ is the $i$ th layer thickness

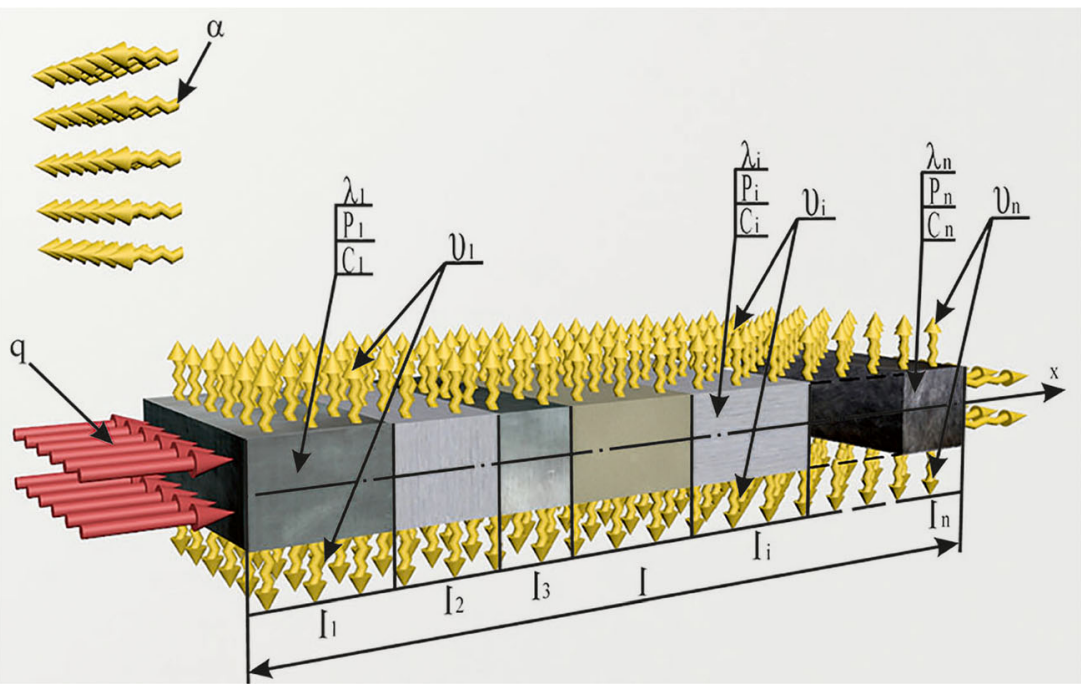


- In the time frame $t \in[0 ; \tau]$, the boundary conditions of the second kind are set; i.e. the heat flow intensity $q$ is given.

- In the time frame $t \in[\tau, T]$, the boundary conditions of the third kind are set, i.e., the heat exchange of the body with the environment according to Newton's law with the heat transfer coefficient $\alpha$.
At the right boundary of the first layer (working layer) and boundaries of the subsequent layers, the condition of full thermal contact in the form of equal temperatures and heat flows, i.e., the boundary conditions of the fourth kind, are set.

The entire boundary conditions for the layered system are as follows:

$$
\begin{array}{lcc}
\frac{\partial U_{1}(0, t)}{\partial \overline{X_{1}}}=\overline{q t \in[0 ; \tau]} & U_{1}\left(\overline{l_{1}}, t\right)=U_{2}(0, t) & U_{3}\left(\overline{l_{2}}, t\right)=U_{3}(0, t) \\
\lambda \frac{\partial U_{1}(0, t)}{\partial \overline{X_{1}}}=\alpha U_{1}(0, t) & \overline{\lambda_{1}} \frac{\partial U_{1}\left(\overline{l_{1}}, t\right)}{\partial \overline{X_{1}}}=\frac{\partial U_{2}(0, t)}{\partial \overline{X_{2}}} & \overline{\lambda_{2}} \frac{\partial U_{2}\left(\overline{l_{2}}, t\right)}{\partial \overline{X_{2}}}=\frac{\partial U_{3}(0, t)}{\partial \overline{X_{3}}} \\
t \in[\tau ; T] &
\end{array}
$$

Therefore, in the one-dimensional scheme, the problem in the form of the set of three thermal conductivity equations and aggregation of the boundary conditions of the second, third, and fourth kind is obtained, i.e., a mixed boundary value problem for the set of Eqs. (1)-(3).

\subsection{Computer simulation of temperature distribution using TEMSS}

Such a problem has no analytical solution and, as the final result, will be solved only numerically, probably, by using computational methods. Solving of the mixed boundary value problem is carried out using the finite element method with quadratic interpolation. Such a method is covered in [39-42]. The TEMSS special programming module has been developed for realizing an implicit numerical scheme, obtained as a result. This module works under DOS or Windows and allows us to calculate the temperature distribution in the metal composite structure depending on the time, the thermal source intensity, the intensity of heat transfer to the process liquid, and also on the thermal and physical properties of the layered system materials.

The module-processing results are the temperature value array and temperature distribution in depth of the workpiece at the current moment. The time moment for which the nominal temperature is calculated is related to the workpiece revolution number. In such a case, heating and cooling stages are distinguished.

In checking the developed model's adequacy, its compliance with well-known thermal physics solutions for the grinding of solid workpieces has been estimated. The difference in the obtained temperature values does not exceed $10 \%$.

\section{Experiments}

\subsection{Direct experimental estimation of the temperature distribution model of the three-layer metal composite structure during grinding}

To check the adequacy of the developed mathematical model of layering tracking, a special experiment on direct temperature measurement at two points of the metal composite structure during grinding was carried out.

The experimental check was carried out using the $3 \mathrm{G} 61$ surface grinder (Fig. 4). The temperatures were measured using thermocouples and stored in H3021-1 recorders (Fig. 5).

Three-layer metal composite samples with chromel-alumel thermocouples fixed at the boundaries of the PCM and metal

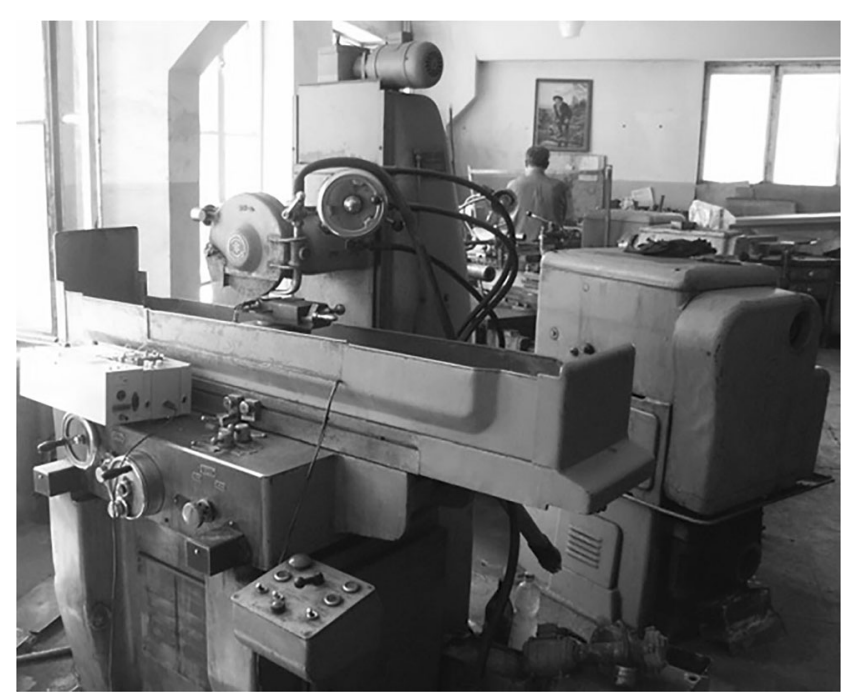

Fig. 4 3G61 surface grinder 


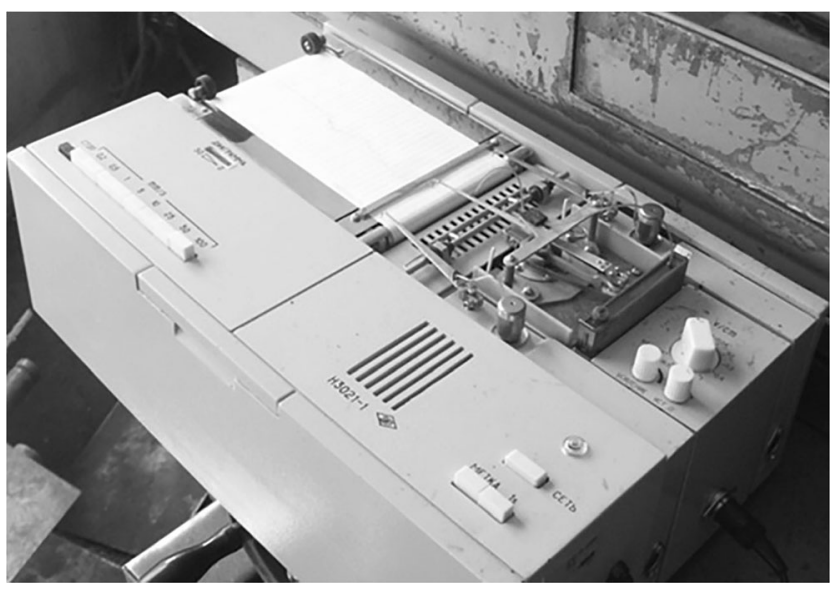

Fig. 5 H3021-1 recorder

layers were ground (Figs. 6 and 7). The sample is presented as a section, and both halves are shown.

During the experiment, samples with the following properties were used: PCM-Belzona 1321, LEO ceramics; PCM layer thicknesses, $\delta, 3,5$, and $8 \mathrm{~mm}$; and working layer thicknesses, $h, 3,5$, and $10 \mathrm{~mm}$.

The experiment was carried out in the following way. The thermocouple ends, fixed in the metal composite sample, were connected to recorders. Grinding was carried out without a process liquid supply due to problems of thermocouple isolation. During the entire grinding process, the temperatures at the PCM layer boundaries were registered. During grinding, the number of table strokes, grinding time, and the allowanceoff were also registered. This allowed calculation of the actual grinding modes. When the grinding was over, the samples were inspected visually for burns and the integrity of the layered structure. The first samples were ground to their full destruction. During the process, the sample destruction moments were registered. Every other sample was ground till the working and PCM layer boundaries had heated up to $100^{\circ} \mathrm{C}$.

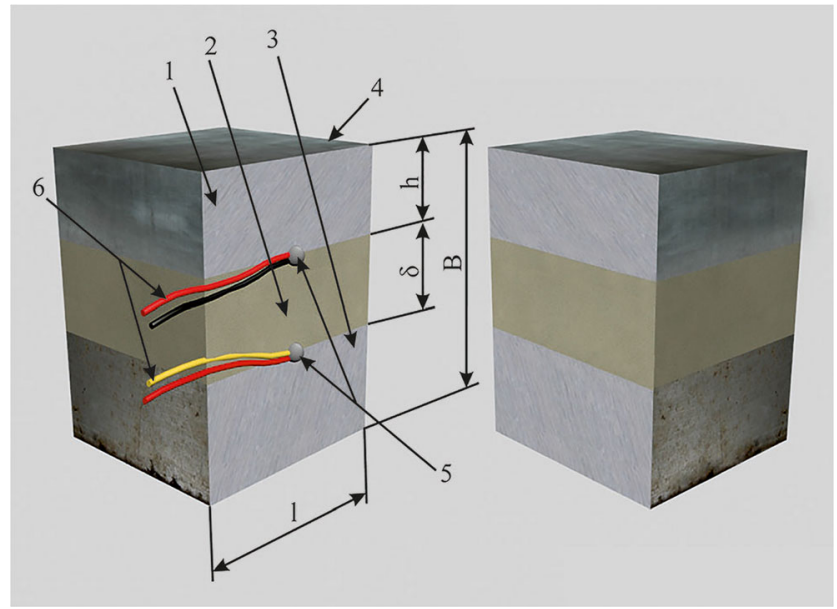

Fig. 6 Scheme of a flat metal composite sample. 1 working layer, 2 PCM layer, 3 basic layer of the structure, 4 surface under grinding, 5 points of fitting the thermocouples, 6 thermocouples

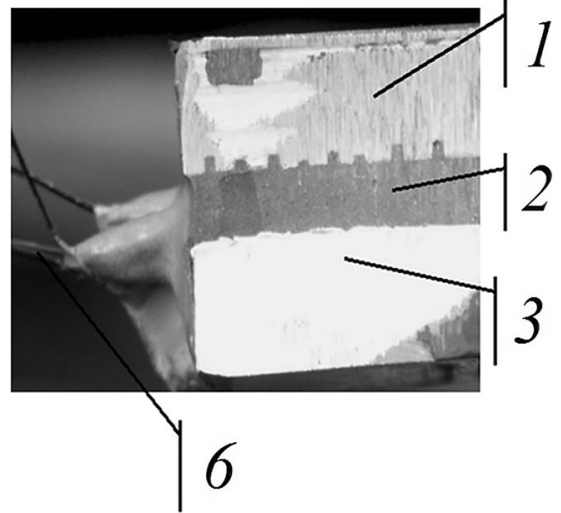

Fig. 7 The metal and composite samples

This method made it possible to carry out the experiment repeatedly without destruction of the metal composite samples.

\subsection{Estimation of adequacy of developed temperature distribution model in the three-layer metal composite structure during grinding}

To estimate the developed model's adequacy, the temperatures obtained experimentally were compared to calculated ones.

\subsubsection{The calculations and experiment example}

The grinding process conditions are as follows: allowance-off during grinding time is $0.02 \mathrm{~mm}$, grinding time is $35 \mathrm{~s}$, the number of table strokes is 40 , and the table stroke speed is $8 \mathrm{~m} / \mathrm{min}$

The data translation is as follows: an average table stroke feed is $0.0005 \mathrm{~mm} /$ table stroke, the cutting power is $0.3 \mathrm{~kW}$, the specific capacity is $0.048 \mathrm{~kW} / \mathrm{mm}^{2}$, and thicknesses of layers correspond to thicknesses of the sample layers.

The heating time (time of the contact arc traveling by the source) approximately corresponds to the time of the heating arc length traveling by the table.

The material of the sample PCM layer is LEO ceramics.

Initial data for TEMSS module: the thermal source capacity $q$ is $48,554,000.0 \mathrm{~W} / \mathrm{m}^{2}$; the rotational frequency of the workpiece $\mathrm{n}$ is $66.0 \mathrm{rpm}$; the contact arc angle is $2.0^{\circ}$; and the number of the system layers is 3 .

The structure of the metal composite structure is described in Table 1.

Diagrams of temperatures versus time, created using the TEMSS module calculations with initial data re-calculated for surface grinding (Table 1), are imposed on the thermograms obtained (Fig. 8).

Comparison of the calculated and experimental dependencies shows that the deviation of temperature values before the 23rd second does not exceed $10 \%$. 
Table 1 The structure of the metal composite structure

1 (working layer) $h, 2$ (PCM layer) $\delta, \quad 3$ (basic layer), $\mathrm{mm} \quad \mathrm{mm} \quad \mathrm{mm}$

\begin{tabular}{llll}
\hline $\begin{array}{l}\text { Layer } \\
\text { thickness }\end{array}$ & $0.003 \times 10^{3}$ & $0.0025 \times 10^{3}$ & $0.0245 \times 10^{3}$ \\
$\chi, \mathrm{m}^{2} / \mathrm{s}$ & $3,676,814$ & $13,245,200$ & $3,676,814$ \\
$\lambda, \mathrm{W} /(\mathrm{m} \mathrm{K})$ & 29.0 & 1.0 & 29.0 \\
\hline
\end{tabular}

At the part of the upper boundary of the polymer composite layer, the experimental curve rises dramatically after the 23rd second compared to the calculated one. Such a rise is related with the temperature of the PCM layer exceeding its heating resistance threshold $\left(170^{\circ} \mathrm{C}\right)$ at the $23 \mathrm{rd}$ second and the ground steel plate separating from the PCM layer. As the thermocouple is fixed on the steel plate, after the layer separation, the temperature data can be considered as related not to the boundary layers but to the lower plate surface, bordering the atmosphere after separation (the heat exchange scheme was dramatically broken). In this case, only the upper plate was heated. In the three-layer system zone, quite a satisfactory matching of the experimental and calculated temperatures is observed.

Therefore, the developed model's functional capability can be concluded considering system layering versus time. The model reflects the nature of the temperatures in the metal composite structure during grinding and can be used for analyzing the layered system's temperature distribution during grinding.

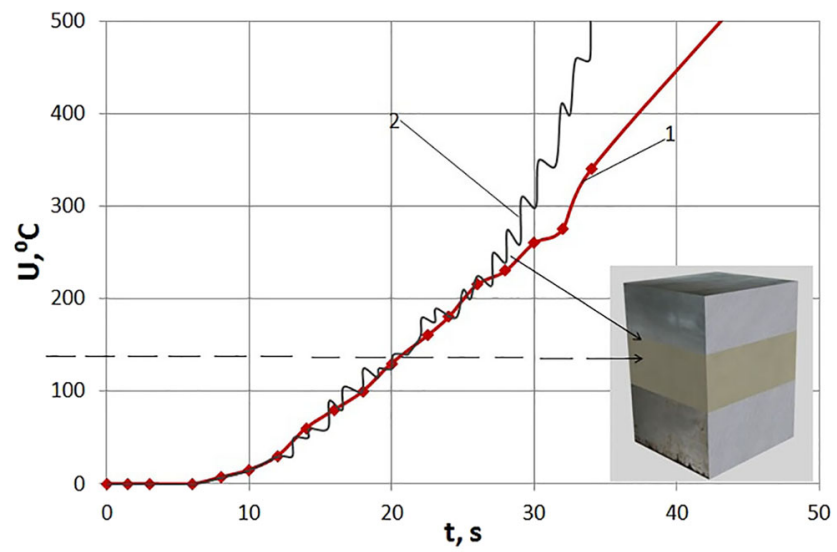

a) the upper boundary of the polymer composite layer

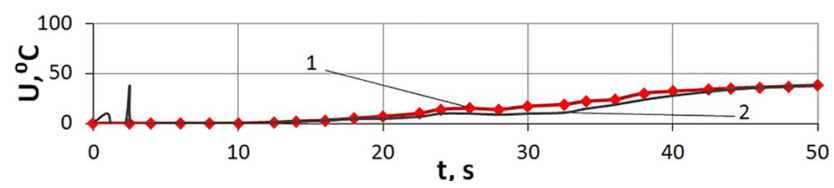

b) the lower boundary of the polymer composite layer

Fig. 8 Imposing the calculated ( $(1)$ and experimental temperatures (2) for the upper boundary of the PCM layer of the metal composite structure with layers $3-2.5-10 \mathrm{~mm}$ thick (PCM material is LEO ceramics)

\section{Materials and methods}

\subsection{Initial data}

The complex analysis of the temperature distribution for the standard metal composite structures, the range of industrial PCMs, and the load range (approximately 1500 fields) was carried out using the developed programming module.

The layered system design parameter values (see Table 2) based on the analysis of the real repair technologies are the same for thermal state modeling as for the stress state analysis. Treatment modes are admitted according to the general mechanical standard grinding modes [43] given in Table 2.

The required grinding area parameters such as the cutting depth $d$, the contact arc length $L_{c}$, and the intensity of heat source $q$ are calculated using the above.

The grinding power, given in Table 2 , should be correlated to the burnless one according to the general mechanical standards [43]. The general mechanical standards recommend burnless power in the range of 115-135 MW/mm. Therefore, concerning the contact arc lengths, the thermal source capacity providing burnlessness is $q=0.15-$ $0.19 \times 10^{9} \mathrm{~W} / \mathrm{m}^{2}$. The heat transfer ratios are given according to the recommendations in [37] as $\alpha=0.23-0.8$.

The thermal and physical characteristics of polymer composite materials according to $[15,44]$ are given in Table 3 .

Following the variable $\sqrt{\chi} / \lambda$, predefining the temperature on the surface heated using the thermal source, three PCM groups could be specified according to their thermal and physical characteristics (Table 4).

The temperature distribution has been calculated for these PCM groups. The main groups are represented by the following PCMs: group 1 is represented by Loctite 641, group 2 by Chester molecular metal super, and group 3 by Devcon C-1.

\section{Results and discussion}

\subsection{Temperature distribution in the grinding cycle}

To find out the impact of system layering, analysis of the temperature distribution in the metal composite structures is worth doing when comparing the temperature distribution in the metal composite structure to those of the all-steel workpiece.

As a metal, steel 45 (the high-quality carbon structural steel 45 composition according to GOST $1050-88$ carbon $\mathrm{C}-$ 0.42-0.5\%, silicon $\mathrm{Si}-0.17-0.37 \%$, magnesium $\mathrm{Mn}-0.5-$ $0.8 \%$, chrome $\mathrm{Cr}$ - no more than $0.25 \%$, and the rest iron $\mathrm{Fe}$ ) is used, and its properties are described in the metals handbook [17]. The treatment parameters correspond to line 5 of Table 2. The PCM layer of the metal composite structure 
Table 2 The grinding conditions

\begin{tabular}{lllllllll}
\hline Nos. & $D, \mathrm{~mm}$ & $\mathrm{n}, \mathrm{rpm}$ & $2 \Delta, \mathrm{mm}$ & $\begin{array}{l}V_{S \mathrm{rad}}, \mathrm{mm} / \\
\mathrm{min}\end{array}$ & $\begin{array}{l}N_{\mathrm{sp}}, \\
\mathrm{W} / \mathrm{mm}\end{array}$ & $f_{r}, \mathrm{~mm} / \mathrm{rev}$ & $L_{c}, \mathrm{~mm}$ & $\begin{array}{l}q \cdot 10^{9}, \\
\mathrm{~W} / \mathrm{m}^{2}\end{array}$ \\
\hline 1 & 50 & 130 & 0.15 & 1.89 & 0.125 & 0.0145 & 0.82 & 0.152 \\
2 & & 160 & 0.5 & 3.11 & 0.19 & 0.0194 & 0.9 & 0.211 \\
3 & & 197 & 1.0 & 4.97 & 0.25 & 0.0252 & 1.08 & 0.231 \\
4 & 100 & 88 & 0.3 & 1.79 & 0.19 & 0.0224 & 1.38 & 0.137 \\
5 & & 110 & 0.5 & 2.21 & 0.24 & 0.0201 & 1.31 & 0.183 \\
6 & & 130 & 1.0 & 3.54 & 0.31 & 0.0272 & 1.52 & 0.204 \\
7 & 160 & 67 & 0.3 & 1.4 & 0.2 & 0.0209 & 1.62 & 0.123 \\
8 & & 82 & 0.5 & 1.75 & 0.24 & 0.0213 & 1.64 & 0.146 \\
9 & 100 & 1.0 & 2.8 & 0.35 & 0.028 & 1.88 & 0.186 \\
\hline
\end{tabular}

is represented by Loctite 641, and its thermal and physical characteristics correspond to line 10 of Table 3 . The design parameters are as follows: the part diameter $D=100 \mathrm{~mm}$, the working layer thickness is $3 \mathrm{~mm}$, and the polymer composite layer thickness is $1 \mathrm{~mm}$.

The following has been established: the workpiece heated in the grinding zone during the first turn has no time to cool down completely. During the second turn, the heating source action is applied on the residual temperature of the first one. Therefore, the temperature distribution should be assessed in regard of the grinding cycle. The temperature distribution development should be considered for the entire grinding cycle, regarding the temperature distribution imposed with every other turn of the workpiece.

The standard grinding cycle consists of the following three parts: the first is the grinding disk approach and penetration, the second is the grinding process itself (allowance cuttingoff), and the third is the dead-stop grinding. In this case, the second part is the basic working process during which the main heat is released. Thus, the workpiece temperature distribution can be analyzed considering this very part of the cycle. The average grinding cycle usually consists of 35 to 70 workpiece turns, according to [37]. Figure 9 shows diagrams of the steel $(a, b)$ and the metal composite $(c, d)$ workpiece heating and cooling in five turns per interval of production grinding (excluding penetration and the dead-stop grinding) up to the 25th turn of the workpiece.

The drawing shows that the residual temperature of the allsteel workpiece during the grinding cycle rises to $300^{\circ} \mathrm{C}$ and reaches $900^{\circ} \mathrm{C}$ in the ground layer of the metal composite structure. At the end of the grinding cycle, the maximum temperatures on the surface and at $3 \mathrm{~mm}$ depth for the allsteel workpiece were 1174.8 and $236.6^{\circ} \mathrm{C}$ and for the metal composite structure were 1756 and $867.2^{\circ} \mathrm{C}$, respectively.

This proves the suggestion of the temperature increasing during the grinding cycle. For the all-steel workpiece, the surface temperature increased by $50 \%$ per cycle. For the metal composite, the temperature increased 2.2 times. The temperature at the work and polymer composite layers boundary increased 30 times during the cycle.

Table 3 Thermal and physical characteristics of PCMs

\begin{tabular}{|c|c|c|c|c|c|c|}
\hline Nos. & Materials & $C, \mathrm{~kJ} / \mathrm{kg} \mathrm{K}$ & $\lambda, \mathrm{W} /(\mathrm{m} \mathrm{K})$ & $\rho, \mathrm{kg} / \mathrm{m}^{3}$ & $\sqrt{\chi} / \lambda$ & Group \\
\hline 1 & Fiberglass & 1.5 & 0.21 & 1.6 & 0.70 & 3 \\
\hline 2 & Carbon fiber & 1.03 & 0.51 & 1.3 & 0.8 & 3 \\
\hline 3 & Fiberglass plastic & 0.8 & 1 & 2.52 & 1.41 & 2 \\
\hline 4 & Polyamide plastics & 2.26 & 0.25 & 1.14 & 0.80 & 3 \\
\hline 5 & Metal polymer materials Chester molecular & 2.59 & 0.3 & 2.3 & 1.33 & 2 \\
\hline 6 & Loctite 3273 & 0.3 & 0.3 & 1.09 & 0.31 & 3 \\
\hline 7 & Loctite 620 & 0.3 & 0.3 & 1.09 & 0.31 & 3 \\
\hline 8 & Loctite 661 & 0.3 & 0.3 & 1.09 & 0.31 & 3 \\
\hline 9 & Anaerobic Loctite & 0.3 & 0.66 & 1.66 & 0.5 & 3 \\
\hline 10 & Loctite 641 & 0.3 & 0.1 & 1.07 & 0.17 & 3 \\
\hline 11 & Devcon A, B, UV, P & 2.59 & 0.57 & 4.4 & 2.54 & 1 \\
\hline 12 & Devcon C-1 & 2.59 & 1.28 & 5.88 & 4.41 & 1 \\
\hline
\end{tabular}


Table 4 PCM groups

\begin{tabular}{llll}
\hline$\sqrt{\chi} / \lambda$ Range & $2.5-5$ & $1.0-2.5$ & Less than 1 \\
\hline Group & 1 & 2 & 3 \\
\hline
\end{tabular}

\subsection{The temperature distribution during grinding of the repair metal composite structures}

Results of the temperature distribution calculations during grinding of the metal composite structures actually used in repair polymer composite technologies, described in [14], are given below.

The calculations are made considering that the grinding is performed with the process liquid supply. The calculations are carried out for three types of metal composite structures, differing in the polymer composite material group used.

- Containing the polymer composite layer of the first group material according to its thermal and physical characteristics (Table 3); Loctite 641 is taken as the group representative;

- Containing the polymer composite material of the second group (such as the metal polymer Chester molecular);

- Containing the polymer composite material of the third group (such as the metal polymer Devcon C-1).

Analysis of the metal composite structure grinding defects, and the temperature distribution features in the metal composite structure during grinding of its working layer, given in [14], showed that the temperature values in the range of specific points are of practical interest. First, two points are specified:

- The outer boundary of the working layer on the ground surface;

- The boundary between the working and PCM layers.

As it follows from the above, the maximum temperature on the ground surface corresponds to the point of leaving the grinding zone for every turn, and the maximum temperatures in the second specific point correspond to the end of the cooling zone for every turn.

Figure 10 shows the temperature curves at the points of the analyzed section of the ground workpiece leaving the grinding zone, i.e., at the moment the thermal source stops heating, and it corresponds to maximum heating of the ground surface. Plots are given for the first 25 turns of the workpiece.

Figure 10 shows that the polymer composite properties considerably influence all the parameters of the temperature distribution, which are the maximum temperature of the

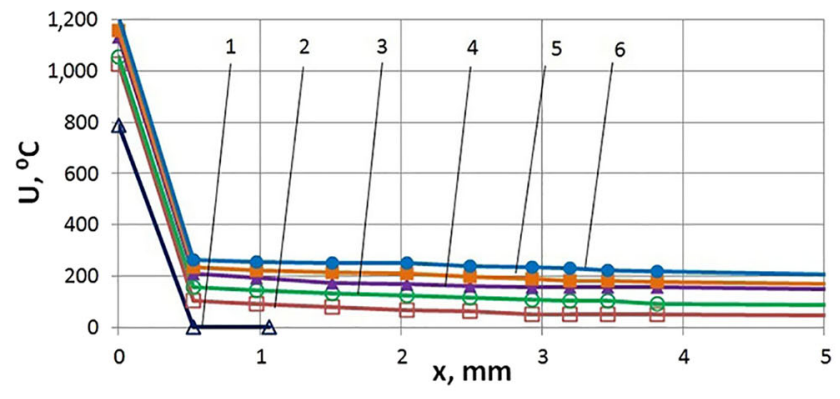

a) the steel work piece (heating)

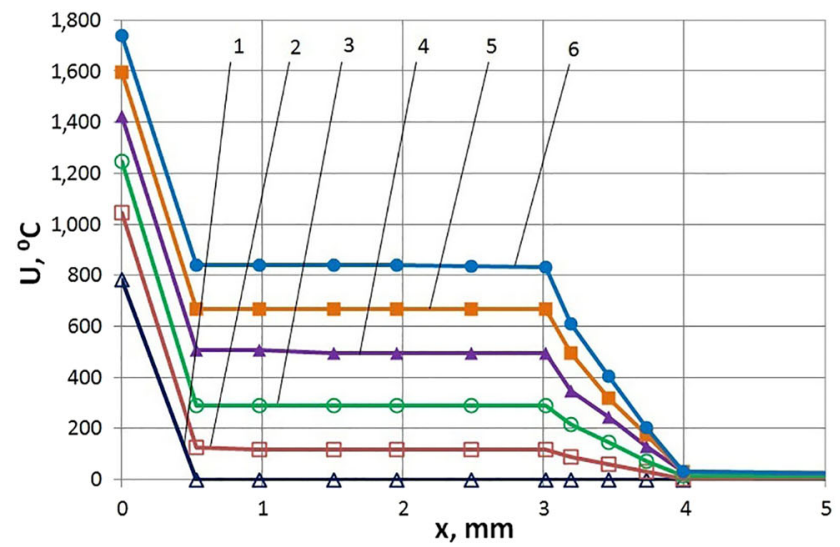

b) the layered system (heating)

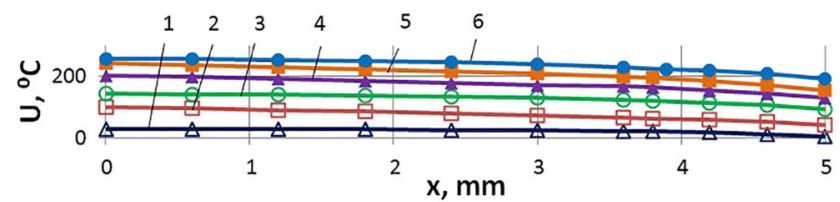

c) the steel work piece (cooling)

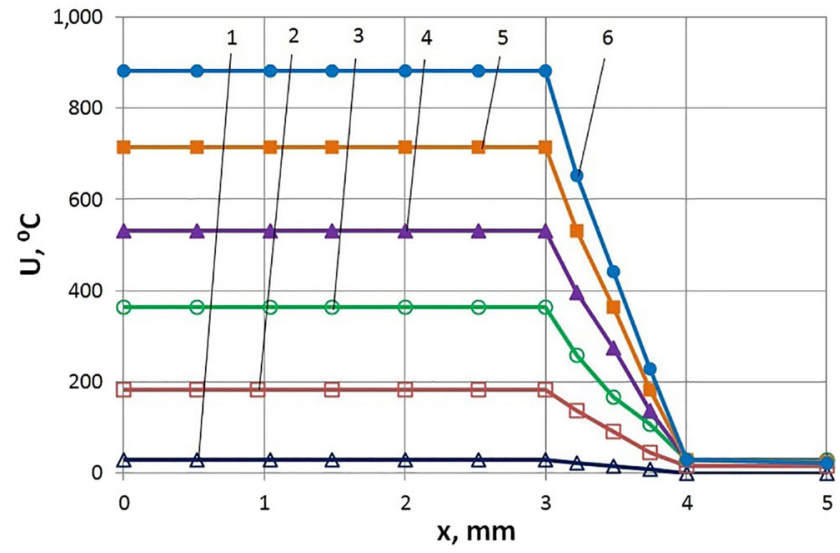

d) group 3 PCMs (cooling)

Fig. 9 Temperature distribution $U$ in-depth $x$ at the moment of leaving the grinding zone, where 1-1 turn, 2-5 turns, 3-10 turns, 4-15 turns, 520 turns, and 6-25 turns

ground surface heating, the working layer heating in the subsurface layers (depths from 1 to $3 \mathrm{~mm}$ ), and heat extraction through the PCM layer.

The rise of temperature distributions in dependence on the number of turns of the workpiece in Fig. 7 shows, 


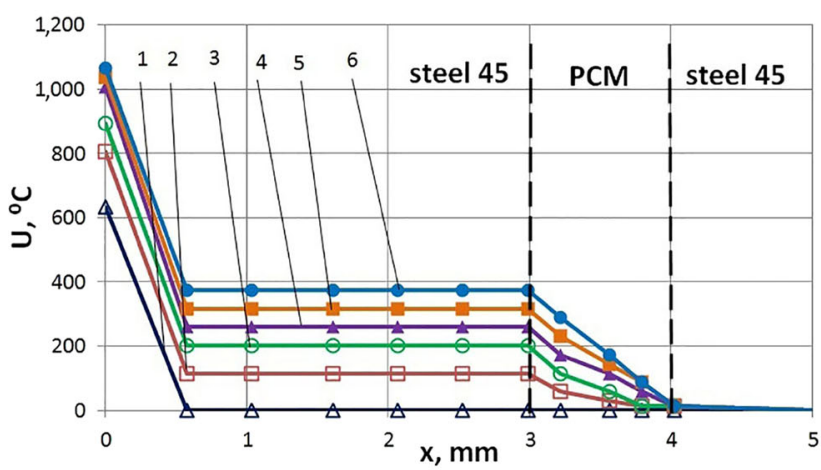

a) group 1 PCMs (heating)

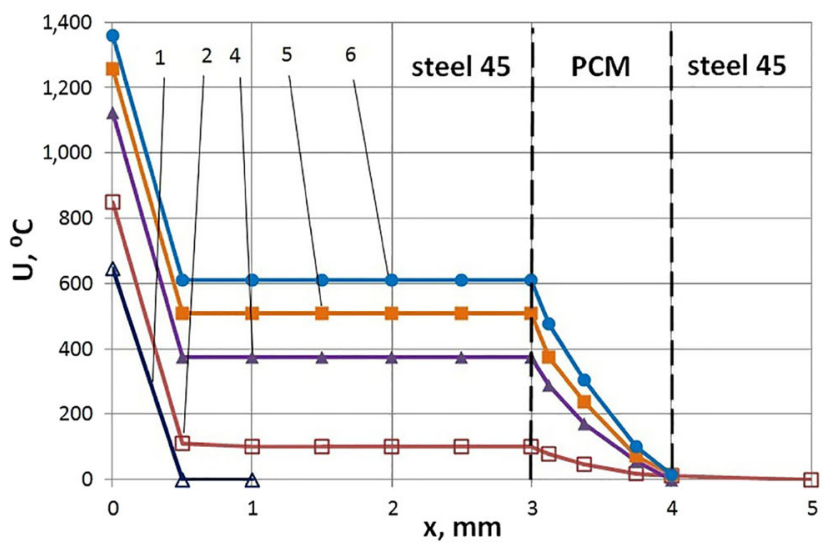

b) group 2 PCMs (heating)

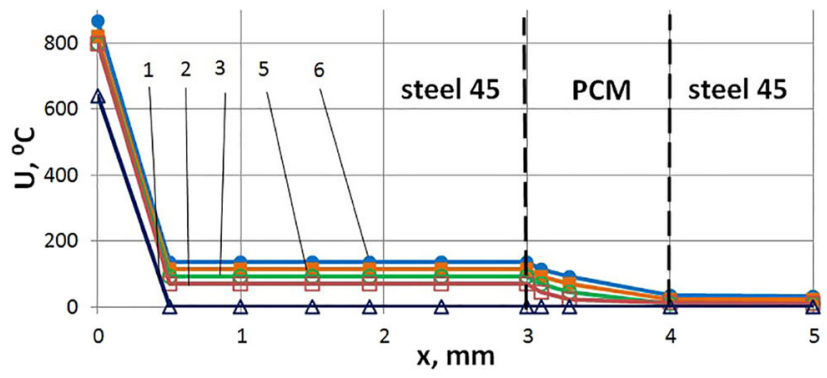

c) group 3 PCMs (heating)

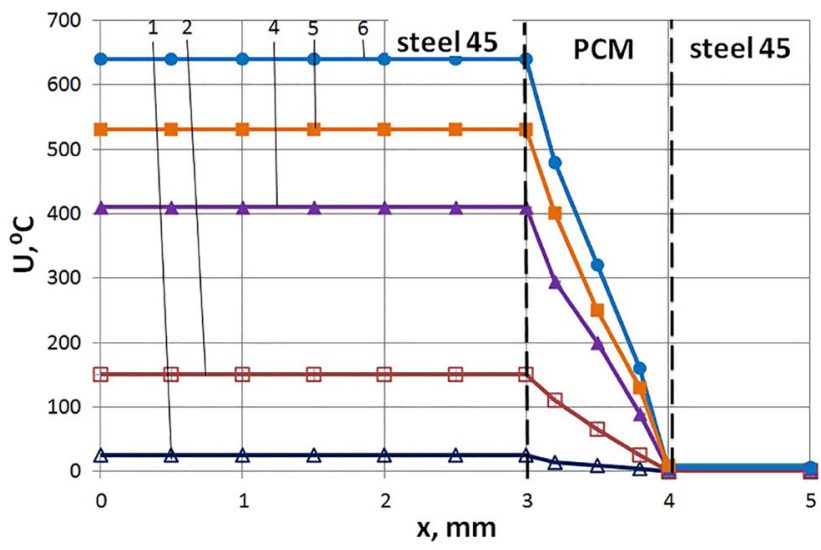

d) group 1 PCMs (cooling)

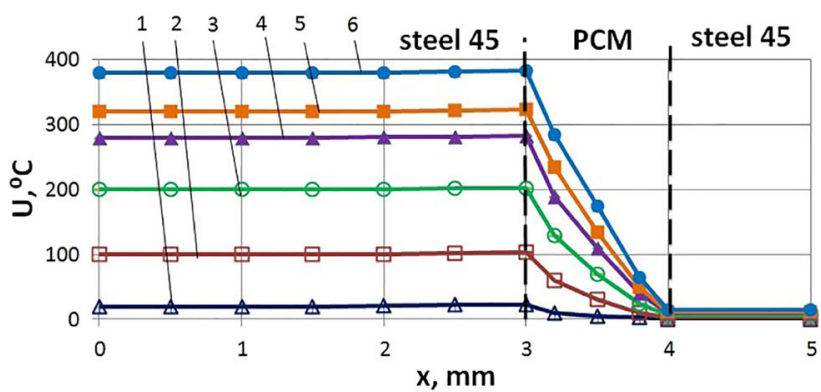

e) group 2 PCMs (cooling)

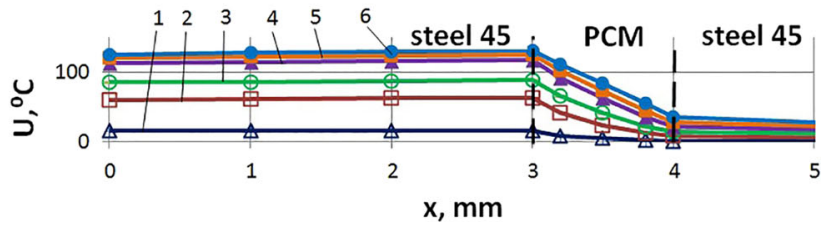

f) group 3 PCMs (cooling)

Fig. 10 The temperature $U$ radial in-depth distribution $x$ at the point of leaving the grinding zone for the metal composite structure $(D=100 \mathrm{~mm}$, $h=3 \mathrm{~mm}, \delta=1 \mathrm{~mm}$; PCMs (groups 1, 2, and 3)), where 1-1 turn, 2-5 turns, 3-10 turns, 4-15 turns, 5-20 turns, and 6-25 turns

firstly, a tendency to thermal saturation of the ground workpiece and, secondly, the polymer composite's impact on the tendency. It is clearly seen that the third group of PCMs' temperature distributions (see Fig. 10c) after the 20 th turn is practically immovable; i.e., the process is close to thermal saturation, but those of the first group of PCMs (see Fig. 10a) show intensive temperature increase.

The impact of the polymer composite layer on the thermal saturation of the metal composite system during grinding is more evident in the temperature curves of the cooling process (see Fig. 10d-f).

\subsection{Impact of the metal composite structure and grinding conditions on critical temperatures}

In Sect. 5.2, two specific points of the metal composite structure have been specified, temperatures in which impact dramatically formation of the grinding defects. The first point is on the ground surface, i.e., on the outer surface of the working layer. The second is the boundary between the working and PCM layers. In terms of defect formation, the defining feature of the temperature distribution at these points is the maximum temperature. These temperatures are suggested to be called critical. 
The first critical temperature is the maximum temperature on the ground surface at the point of leaving the grinding zone.

The second critical temperature is the maximum temperature on the outer boundary of the PCM layer when entering the grinding zone.

\subsection{Effect of the intensity of heat source}

The intensity of heat source directly depends on the grinding modes. So it makes sense, first of all, to assess the impact of the thermal source capacity on the critical temperatures of the metal composite structure when grinding. Figure 11 shows the dependence of the critical temperatures of the ground workpiece on the thermal source capacity both on the workpiece surface (a) and on the boundary of the working and polymer composite layers (b).

Figure 11 shows that if the heat source intensity increases five times, the temperature on the ground surface of the metal composite structure increases by 3.8 to 4 times, and the temperature at the boundary of the working and polymer composite layers increases by 5.8 to 8 times.

Therefore, the heat source intensity has a great impact on the critical temperatures of the metal composite structure. An almost proportional relationship is observed. What is more, if the proportionality factor of the first critical temperature is less than 1 and is equal to $0.76-0.8$, then that of the second critical temperature is more than 1 and is equal to 1.16 to 1.6 .

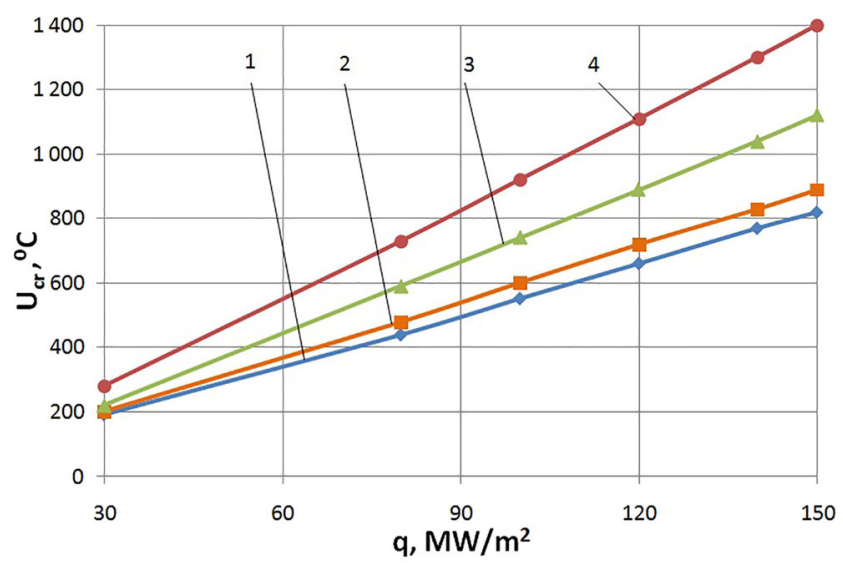

a) the ground surface

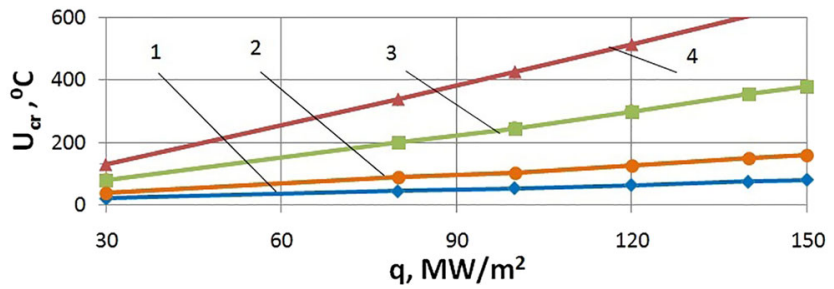

b) the working and PCM layers boundary

Fig. 11 Effect of intensity of heat source $q$ on the critical temperatures $U_{\mathrm{cr}}$ of the metal composite structure $(D=100 \mathrm{~mm}, h=3 \mathrm{~mm}, \delta=1 \mathrm{~mm})$, where 1 steel, 2 group 1 PCMs, 3 group 2 PCMs, 4 group 3 PCMs

\subsection{Impact of the grinding cycle duration}

As described in Sect. 5.2, due to the temperature imposition by the end of the turn, the ground workpiece cannot cool completely, so temperature distribution is imposed consequently with every turn. That is why the grinding time (grinding cycle duration) turns out to be a factor of the ground workpiece heating that is as important as the thermal source capacity.

Figure 12 shows that the critical temperature changes during the grinding cycle at every five turns of the workpiece. The presented dependencies show that a reduced heating of the metal composite structure during its working layer grinding because of decreased capacity, i.e., decreased in-feed, is quite possible but can lead to a great loss of efficiency.

As a comparison, Fig. 12 shows that the curves of the critical temperatures increase for the all-steel workpiece as well. Here, the first critical temperature is the maximum heating of the ground surface. The second critical temperature is the maximum heating in-depth, at the boundary of the working and polymer composite layers of the metal composite structure.

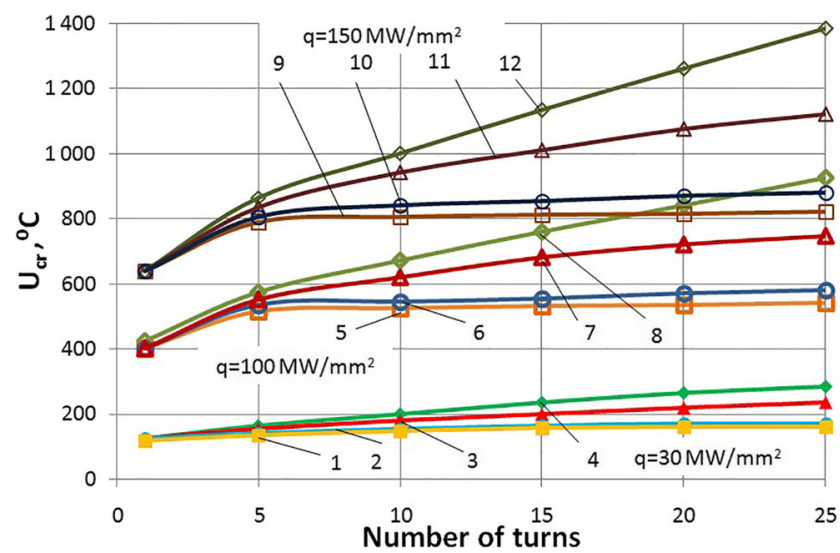

a) the first critical temperature (maximum heating)

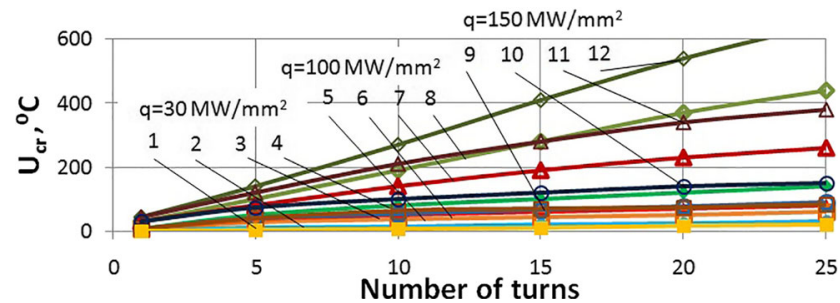

b) the second critical temperature (maximum heating)

Fig. 12 Effect of grinding time on the critical temperatures $U_{\text {cr }}$ of the metal composite structure $(D=100 \mathrm{~mm}, h=3 \mathrm{~mm}, \delta=1 \mathrm{~mm})$, where 1 steel $\left(q=30 \mathrm{MW} / \mathrm{mm}^{2}\right), 2$ Devcon $\left(q=30 \mathrm{MW} / \mathrm{mm}^{2}\right), 3$ Chester metal $\left(q=30 \mathrm{MW} / \mathrm{mm}^{2}\right), 4$ Loctite $\left(q=30 \mathrm{MW} / \mathrm{mm}^{2}\right), 5$ steel $(q=100 \mathrm{MW} /$ $\left.\mathrm{mm}^{2}\right), 6$ Devcon $\left(q=100 \mathrm{MW} / \mathrm{mm}^{2}\right), 7$ Chester metal $(q=100 \mathrm{MW} /$ $\left.\mathrm{mm}^{2}\right), 8$ Loctite $\left(q=100 \mathrm{MW} / \mathrm{mm}^{2}\right), 9$ steel $\left(q=150 \mathrm{MW} / \mathrm{mm}^{2}\right), 10$ Devcon $\left(q=150 \mathrm{MW} / \mathrm{mm}^{2}\right), 11$ Chester metal $\left(q=150 \mathrm{MW} / \mathrm{mm}^{2}\right), 12$ Loctite $\left(q=150 \mathrm{MW} / \mathrm{mm}^{2}\right)$ 
Figure 12 shows that reduction of the number of workpiece turns per cycle results in a considerable lowering of the maximum temperatures both on the ground surface and at the working and PCM layer boundaries. Reduction of the number of turns in the cycle from 25 to 5 for steel results in a temperature decrease on the ground surface of up to $22 \%$ and for the metal composite structure of 26 to $53 \%$. Reduction of the number of turns from 25 to 5 results in a temperature decrease of up to $96 \%$ for the metal composite structure.

Therefore, the critical temperature values for the metal composite structures during grinding can be influenced greatly by changes in the number of turns of the workpiece per grinding cycle.

\subsection{Effect of the metal composite structure}

Figure 13 shows, in bar graph form, the dependence of the critical temperatures for metal composite structures on basic thermal, physical, and mechanical parameters such as the thickness of the working and polymer composite layers (see Table 1).

The bar graph in Fig. 13 shows the critical temperature values at the end of the grinding cycle, i.e., their maxima.

The bar graphs show that any changes of the metal composite structure result in complex changes of the maximum critical temperatures at the end of the cycle, both on the surface of the working layer and at the boundary of the working and polymer composite layers.

In the first group of PCMs (Loctite 641), the change of the working and PCM layer depth correlation from $h=3 \mathrm{~mm}$, $\delta=1 \mathrm{~mm}$ to $h=5 \mathrm{~mm}, \delta=3 \mathrm{~mm}$ (the first case) leads to lowering of the maximum critical temperatures on the ground

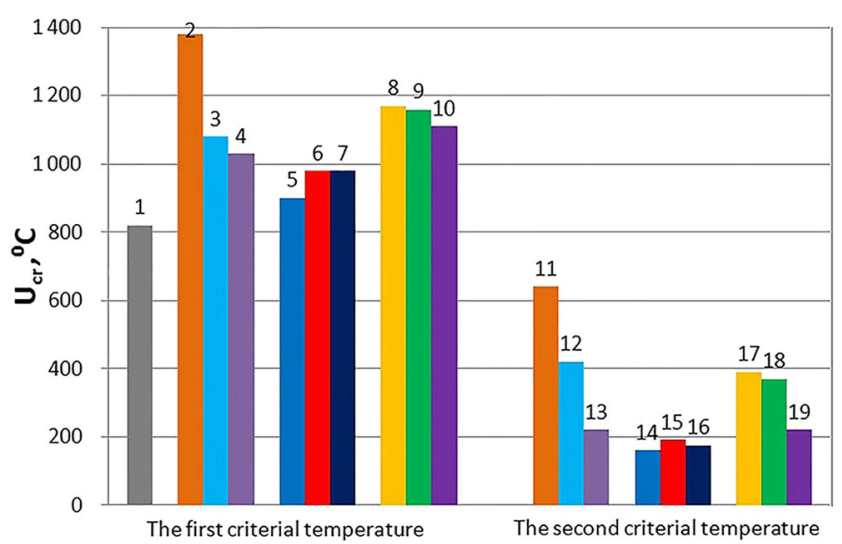

Fig. 13 Effect of the metal composite structure on the critical temperature maxima $U_{\mathrm{cr}}$, where 1 metal; 2,11 group $1 \mathrm{PCM}$ ( $h=3 \mathrm{~mm}, \delta=1 \mathrm{~mm}) ; 3,12$ group 1 PCMs $(h=5 \mathrm{~mm}, \delta=3 \mathrm{~mm}) ; 4$, 13 group $1 \mathrm{PCMs}(h=8 \mathrm{~mm}, \delta=5 \mathrm{~mm}) ; 5,14$ group $3 \mathrm{PCMs}(h=3 \mathrm{~mm}$, $\delta=1 \mathrm{~mm}) ; 6,15$ group $3 \mathrm{PCMs}(h=5 \mathrm{~mm}, \delta=3 \mathrm{~mm}) ; 7,16$ group 3 PCMs ( $h=8 \mathrm{~mm}, \delta=5 \mathrm{~mm}) ; 8,17$ group 2 PCMs $(h=3 \mathrm{~mm}, \delta=1 \mathrm{~mm})$; 9, 18 group 2 PCMs $(h=5 \mathrm{~mm}, \delta=3 \mathrm{~mm}) ; 10,19$ group 2 PCMs $(h=8 \mathrm{~mm}, \delta=5 \mathrm{~mm})$ surface by up to $22 \%$, and the correlation $h=8 \mathrm{~mm}, \delta=5 \mathrm{~mm}$ resulted in lowering them by $24 \%$.

In the third group of PCMs (Devcon C-1), the same changes resulted in increase of the maximum critical temperatures in the first case by $8 \%$ and in the second one by $9 \%$.

The change of the metal composite structure also results in temperature changes at the boundary of the working and PCM layers.

In the first group of PCMs (Loctite 641), the change of the structure in the first case resulted in lowering the critical temperature maxima by $33 \%$ and in the second one by $60 \%$. In the third group of PCMs (Devcon C-1), in the first case, the critical temperature maxima increased by $34 \%$ and in the second one by $7 \%$.

Therefore, the change of the metal composite structure (increase of thickness of both the working surface and the PCM layer) for materials of groups 1 and 2 results in lowering the maximum heating temperatures on the ground surface and in the PCM layer.

In the second group of PCMs, the change of layer correlation to $h=5 \mathrm{~mm}, \delta=3 \mathrm{~mm}$ resulted in just some lowering of the critical temperature maximum. The change of layer correlation to $h=5 \mathrm{~mm}, \delta=8 \mathrm{~mm}$ determined further reduced heating of the working layer during grinding. The same patterns for this group of PCMs could be observed for the second critical temperature maxima, but in an enhanced version, as the change of layer correlation to $h=8 \mathrm{~mm}, \delta=5 \mathrm{~mm}$ leads to lower heating of the working and PCM layer boundary by $80 \%$.

Therefore, the metal composite structure strongly influences the maximum heating of the ground working layer and the polymer composite layer beneath. The developed temperature model considers this influence, so calculations of defectless grinding modes of the metal composite structures can be based on the model.

Thus, it has been established that when grinding the working steel layer of the metal composite structure using standard modes for the steel workpiece, as a rule, the temperatures in the working and polymer composite layers exceed extreme values for the layer materials.

\section{Conclusions}

It should be noted that

(1) The developed mathematical model of temperature distribution in the metal composite structure during grinding of its working layer adequately considers different thermal and physical characteristics of the system layer materials and, being realized as the TEMSS programming module, allows us to calculate the temperature 
distribution features in the system layers depending on grinding modes and time.

(2) Analysis of the temperature distribution for standard metal composite structures during grinding showed that industrial polymer composite materials with low thermal conductivity and higher heat source intensity substantially slow the working layer's cooling processes and thus exhibit increased heating of the metal layer being ground.

(3) Analysis of the stress and temperature distribution in the metal composite structures during grinding of their working layers showed that when using standard grinding modes, the PCM layer stress, and temperatures on the ground material and in the polymer composite layer, as a rule, might exceed extreme values for the layer materials.

(4) The performed classification of industrial PCMs according to their thermal and physical characteristics makes it possible to prepare general guidelines on temperatures of the metal composite structure heating for material groups.

Acknowledgements We thank the editors of the journal "Composites Part B: Engineering" and especially David Hui, Professor of the University of New Orleans, New Orleans, United States, for the essential comments about the article. We thank also the editor of the journal "International Journal of Advanced Manufacturing Technology" and especially David W. Russell, Professor of the Penn State Great Valley, Malvern, United States, for quick and high quality review articles. The authors also honor the memory of deceased Prof. Anatoly Koshin, Chelyabinsk, Russia, as it was he who helped them with the mathematical formulation of their studies several years ago. The authors thank Mary Ilieva, Chelyabinsk, Russia, for a preliminary translation of the article into English.

\section{Compliance with ethical standards}

Funding The research was carried out within the South Ural State University Project 5-100 from 2016 to 2020 aimed to increase the competitiveness of leading Russian universities among the world research and educational centers. The work was supported by Act 211 Government of the Russian Federation, contract № 02.A03.21.0011.

Open Access This article is distributed under the terms of the Creative Commons Attribution 4.0 International License (http:// creativecommons.org/licenses/by/4.0/), which permits unrestricted use, distribution, and reproduction in any medium, provided you give appropriate credit to the original author(s) and the source, provide a link to the Creative Commons license, and indicate if changes were made.

\section{References}

1. Skorokhod VV (2003) Layered composites: structural classification, thermophysical and mechanical properties. Powder Metall Met Ceram 42(9-10):437-446. doi:10.1023 /B:PMMC.0000013215.36378.50
2. Tan CK, Blackwood DJ (2003) Corrosion protection by multilayered conducting polymer coatings. Corros Sci 45(3):545-557. doi:10.1016/S0010-938X(02)00144-0

3. Kryachek VM (2005) Friction composites: traditions and new solutions (review). Part 2. Composite materials. Powder Metall Met Ceram 44(1-2):5-6. doi:10.1007/s11106-005-0050-1

4. Shen YL, Suresh S (1996) Steady-state creep of metal-ceramic multilayered materials. Acta Mater 44(4):1337-1348. doi:10.1016/1359-6454(95)00294-4

5. Kruchinin SV, Lipatov AV, Ovcharenko LV, Fetkulin MM (2002) Metal polymer composite materials for the repair and restoration of engineering equipment. Remont Vosstan Moderniz 1:37-41

6. Shmidt IV, Dyakonov AA (2014) Modeling of stressed state during the processing of laminated surfaces. Lecture Notes Eng Comput Sci 2:914-917

7. Yoo SY, Kim CH, Kweon JH, Choi JH (2016) The structural analysis and strength evaluation of the rivet nut joint for composite repair. Comp Struct 136:662-668. doi:10.1016/j. compstruct.2015.11.012

8. Goncharov AB (1999) Application of advanced technologies with the use of polymer composite materials at the "Mosintrast" company. Svarochn Proizv 10:7-24

9. Malcolm J (2009) To replace or to wrap - the standardisation of composite repair. Reinf Plast 53(7):42-44. doi:10.1016 /S0034-3617(09)70288-7

10. Rudawska A (2012) Bonded joints strength of aramid-epoxy and graphite-epoxy composites. In: ECCM 2012 - Composites at Venice, Proceedings of the 15th European Conference on Composite Materials

11. Raykhere SL, Kumar P, Singh RK, Parameswaran V (2010) Dynamic shear strength of adhesive joints made of metallic and composite adherents. Mater Des 31(4):2102-2109. doi:10.1016/j.matdes.2009.10.043

12. Mirman IB (1991) Effects of peeling stresses in bimaterial assembly. J Electron Packag, Trans ASME 113(4):431-433. doi:10.1115/1.2905433

13. Pashnyov VA, Pimenov DY (2015) Stress analysis of a three-layer metal composite system of bearing assemblies during grinding. Mech Compos Mater 51(1):109-128. doi:10.1007/s11029-015-9478-7

14. Pashnyov VA (2005) Increased effectiveness of grinding of the 3layer metal composite systems. Abstract of thesis of Ph.D. in Engineering: 05.02.08. Chelyabinsk

15. Koshin AA, Pashnyov VA (2004) Features of grinding of threelayer metal-composite systems. Abrasive production Coll works, Izdat. YuUrGU, Chelyabinsk, pp 79-84

16. Handbook of Composites (1988) Vol. 2. Lubin G, editor. Transl. from English, Geller AB et al.; Ed. B. Geller, Moscow: Mashinostroenie

17. Handbook of Metals (1976) Vol. 2. Rachschtadt AG, Brostrom VA, editors, Moscow: Mashinostroenie

18. Davis LC, Artz BE (1995) Thermal conductivity of metal-matrix composites. J Appl Phys 77(10):4954-4960. doi:10.1063/1.359302

19. Hasselman DPH, Johnson LF (1987) Effective thermal conductivity of composites with interfacial thermal barrier resistance. J Compos Mater 21(6):508-515. doi:10.1177/002199838702100602

20. Liu M (2012) Surface quality prediction in precision cylindrical grinding of YG3 cemented carbide based on improved ANFIS. Zhongguo Jixie Gongcheng/China Mech Eng 23(9):1070-1074. doi:10.3969/j.issn.1004-132X.2012.09.014

21. Krivov GA, Lupkin BV (1995) Machining of polymer-composite materials. Compos Manuf Technol 1:155-218

22. Ren X, Liu Z (2016) Influence of cutting parameters on work hardening behavior of surface layer during turning superalloy Inconel 718. Int J Adv Manufact Technol 86(5-8):2319-2327. doi:10.1007/s00170-016-8350-9 
23. Suresh P, Marimuthu K, Ranganathan S (2013) Determination of optimum parameters in turning of aluminium hybrid composites. Int Rev Mech Eng 7(1):115-125

24. Denkena B, Köhler J, Hahmann D (2012) Grinding of steel-ceramic-composites. Int J Abrasive Technol 5(2):175-186. doi:10.1504 /IJAT.2012.048546

25. Biermann D, Feldhoff M (2012) Abrasive points for drill grinding of carbon fibre reinforced thermoset. CIRP Ann Manuf Technol 61: 299-302. doi:10.1016/j.cirp.2012.03.096

26. Yuan HP, Gao H, Liang YD (2010) Fabrication of a new-type electroplated wheel with controlled abrasive cluster and its application in dry grinding of CFRP. Int J Abras Technol 3(4):299-315. doi:10.1504/IJAT.2010.036963

27. Sasahara H, Kikuma T, Koyasu R, Yao Y (2014) Surface grinding of carbon fiber reinforced plastic (CFRP) with an internal coolant supplied through grinding wheel. Prec Eng 38:775-782. doi:10.1016/j.precisioneng.2014.04.005

28. Shmidt IV, D'yakonov AA (2014) Thermal behavior in the grinding of laminar systems. Rus Eng Res 34(12):817-821. doi:10.3103/S1068798X14120223

29. Malkin S, Guo C (2007) Thermal analysis of grinding. CIRP Ann Manuf Technol 56(2):760-782. doi:10.1016/j.cirp.2007.10.005

30. Jiang J, Ge P, Sun S, Wang D, Wang Y, Yang Y (2016) From the microscopic interaction mechanism to the grinding temperature field: an integrated modeling on the grinding process. Int J Mach Tools Manuf 110:27-42. doi:10.1016/j.ijmachtools.2016.08.004

31. Korchak SN (1971) Theory of impact of the processing factors on the increase of effectiveness in grinding the steel parts. Thesis of Doctor of Engineering: 05.02.08. Chelyabinsk

32. Efremov VD, Zheludkevich MS, German ML (2000) Computer thermal model for hardening grinding. J Eng Phys Thermophys 73(2):428-435. doi:10.1007/BF02681753

33. Skuratov DL, Ratis YL, Selezneva IA, Pérez J, Córdoba PF, Urchueguia JF (2007) Mathematical modelling and analytical solution for workpiece temperature in grinding. Appl Math Model 31:1039-1047. doi:10.1016/j.apm.2006.03.023

34. Li CH, Li JY, Wang S, Zhang Q (2013) Modeling and numerical simulation of the grinding temperature field with nanoparticle jet of MQL. Advances in Mechanical Engineering Article ID 986984, 9 pages. doi:10.1155/2013/986984

35. Shmidt IV, Dyakonov AA (2016) Numerical solution of the thermophysical task of grinding of the laminated system consisting of polymer-composite materials. Procedia Eng 150:980-986. doi:10.1016/j.proeng.2016.07.074

36. Ostrovskiy VI (1981) Theory of the grinding process. Publ. House of the Leningrad University, Leningrad

37. Reznikov AN (1981) Thermal physics of material machining processes. Mashinostroenie, Moscow

38. Yakimov AV, Kazimirchik YuA, Sipaylov VA (1964) Studies of temperatures in the grinding zone. Vestnik Mashinostroeniya 8

39. Koshin AA (1971) Studies of functional relations between limiting conditions and thermal criteria of diamond abrasive treatment. Abstract of thesis of Ph.D. in Engineering: Chelyabinsk. ChPI

40. Gallagher R (1975) Finite element analysis fundamentals. Prentice Hall, Englewood Cliffs, NJ

41. Hufenbach W, Gruber B, Gottwald R, Lepper M, Zhou B (2010) Analytical and experimental analysis of stress concentration in notched multilayer composites with finite outer boundaries. Mech Compos Mater 46(5):531-538. doi:10.1007/s11029-010-9169-3

42. Roékowicz M, Smal T (2011) Durability of Belzona 1111 and Belzona 1812 adhesive composites. Polimery/Polymers 56(6): 471-477

43. (1967) Machine-building standards of cutting modes for technical standardization of works on grinding lapping and finishing machines. Moscow: NIItruda

44. Tulinov AB, Goncharov AB (2003) New composite materials for the assembly and repair work. Sbor Mashinostr Priborostr 7:26-28 